\title{
Resistance Factor Calculations for Load Resistance Factor Design (LRFD) of MSW Landfill Slopes
}

\author{
B Munwar Basha ${ }^{1}$, M. ASCE and Raviteja KVNS ${ }^{2}$ S.M. ASCE
}

${ }^{1}$ Asst. Professor, Dept. of Civil Engineering, Indian Institute of Technology Hyderabad, Kandi, Sangareddy 502285, India, Email: basha@iith.ac.in

${ }^{2}$ Research Scholar, Dept. of Civil Engineering, Indian Institute of Technology Hyderabad, Kandi, Sangareddy 502285, India, Email: kvnsravi.teja@gmail.com

\begin{abstract}
It is obvious to note that there is a significant amount of variability connected with shear parameters of Municipal Solid Waste (MSW) landfills. To ensure uniform safety and reliability, the design approaches in the US have progressively transformed to the load and resistance factor design (LRFD) format. It may be desirable to the successful development and adoption of reliability based resistance factors for the design of landfill slopes taking into account the significant variability of shear strength parameters. The exhaustive studies reported on shear parameters of MSW are compiled and reviewed. The mean, standard deviation and coefficient of variation $(\mathrm{COV})$ associated with shear parameters are obtained using statistical analysis. The probability density functions (PDF) are plotted for unit weight, cohesion and friction angle. The PDFs show that high range of variability associated with shear parameters and should be given due consideration in the optimum designs. Therefore, the present work reports a procedure for determining the resistance factors for stability number (in terms of unit weight, cohesion) and friction angle of MSW in accordance with LRFD of MSW landfill slopes that target a specific reliability index. A simple first-order reliability method (FORM) is reported to compute the ranges for the resistance factors. Perhaps, this is the first study to propose resistance factors for the design of MSW slopes. The stability number (in terms of unit weight, cohesion) and friction angle of the MSW are treated as random variables. The Spencer method of slices has been employed to formulate the performance function against the sliding failure of finite slopes. It is illustrated that the uniform safety levels can be obtained by using the proposed resistance factors.
\end{abstract}

\section{INTRODUCTION}

The stability of municipal solid waste (MSW) landfill slopes is the major concern in the landfill design. The stability of MSW landfill should include the stability of waste dump, final cover system, bottom liner as well as the stability of foundation soil. The slope stability of MSW landfills is influenced by the various parameters. The design of landfill slopes should consider the geometry of the design section and the shear strength parameters of MSW. Probabilistic analysis is quite popular in dealing with uncertainties 
associated with MSW. In order to conduct the probabilistic stability analysis, it is important to know basic statistical data of uncertain parameters associated with MSW which are included in the analysis.

\section{Studies on Probabilistic Analysis of Soil Slopes}

Hassan \& Wolff (1999) proposed an algorithm for the computation of critical reliability index for soil slopes. The surfaces of a minimum factor of safety and reliability index were examined. Malkawi and Abdulla (2000) used the first order second-moment method (FOSM) and Monte Carlo simulation (MCS) method of reliability analysis of the soil slopes. Low (2003) implemented Spencer's method of slices for a probabilistic approach to slope stability. Xue and Gavin (2007) reported a new approach to determine the minimum reliability index by taking into account the uncertainty associated with the soil properties. Bhattacharya and Dey (2010) coupled first order reliability method (FORM) with the ordinary method of slices (OMS) for computation of factor of safety and reliability index. Basha and Babu (2013) and Basha and Babu (2014) reported the reliability-based LRFD for external seismic stability of reinforced soil walls. Review of literature clearly indicates that the LRFD approach for the design of MSW landfill slopes is not paid any attention.

\section{Need for LRFD for MSW Landfill Slopes}

The AASHTO has been progressively converted from Allowable Stress Design (ASD) to LRFD methods. The major objective of LRFD is to achieve consistent levels of safety and reliability when the design parameters are random. However, the conventional factor of safety method using limit equilibrium approach cannot handle the variability. Moreover, the LRFD can improve the efficiency and accuracy of designs with small changes to existing design procedures. A considerable research work has been reported to develop LRFD methods, which include specific load and resistance factors to facilitate conversion from ASD to LRFD procedures. Adequate LRFD guidelines are available in the literature for the use by researchers. However, the design of MSW landfill slopes considering the variability associated with MSW is severely lacking.

\section{OBJECTIVES OF THE PRESENT STUDY}

The reliability based studies reported in the literature mostly discussed on soil slopes. It is interesting to note that a few studies reported regarding the reliability analysis of MSW slopes. Consequently, there is a deficiency in understanding the mechanism behind the MSW slope failures. The present work is focused on LRFD approach for slope reliability analysis by taking into account the variability associated with the shear strength parameters. Spencer (1967) method is employed in the current study to perform MSW slope stability analysis. The effort made here is perhaps the pioneering study to propose a LRFD for the reliability assessment of MSW slopes. 


\section{ESTIMATION OF VARIABILITY ASSOCIATED WITH MSW PROPERTIES}

As discussed earlier, precise quantification of the variability of MSW shear strength properties is required for the probability based design of landfill slopes. Stability of MSW slopes depends mainly on the properties of the waste materials including unit weight, friction angle, cohesion, and pore water pressure. The age of MSW, heterogeneous nature, the degree of biodegradation and degree of decomposition are the factors that affect the shear strength considerably. The uncertainty can be represented using probability distribution function (PDF) which is further characterized by mean and standard deviation of the design parameters $(\gamma, c$ and $\phi)$.

The ranges of MSW properties like unit weight and shear strength parameters (cohesion and friction angle) have been collected from review of literature published from 1984 to 2016. The data is divided into various bins and plotted as histograms to represent the variability precisely. The type of probability distribution is identified for unit weight, cohesion and friction angle. Histograms are drawn by taking the lower bounds of parameters. It can be noted from Figs. 1, 2 and $\mathbf{3}$ that the normal distribution appears to be a sensible decent model for the observed magnitudes of unit weight $(\gamma)$. Further, Weibull and Gumbel minimum distributions appear to be sensibly decent models for observed values of cohesion $(c)$ and internal friction angle $(\phi)$ respectively. The optimized values mean and standard deviation of MSW properties are shown in Table 1. The basis for the optimization is the minimum error associated with quantile-quantile $\left(\varepsilon_{Q Q}\right)$, probability-probability $\left(\varepsilon_{P P}\right)$ and cumulative distribution function $\left(\varepsilon_{C D F}\right)$.

\section{SPENCER METHOD OF SLICES FOR MSW SLOPE STABILITY}

This method considers both the interslice forces, assumes a constant interslice force function and satisfies both moment and force equilibrium simultaneously and computes the factor of safety. The MSW slope geometry with the method of slices is shown in Fig. 4(a). The slice considered to write force and moment equilibrium equations is shown in Fig. 4(b). Considering the force equilibrium $\left(\sum F_{h}\right)$ and moment equilibrium $\left(\sum F_{m}\right)$ of the whole soil mass and solving for the factor of safety, the following two equations can be derived:

$$
\begin{aligned}
F S_{\text {Spencer_f }_{-}}= & \frac{\sum_{i=1}^{n} T_{i, \mathrm{lim}}}{\sum_{i=1}^{n} T_{i}}=\frac{\sum_{i=1}^{n}\left(c d l_{i}+N_{i} \tan \phi\right) \times \cos \theta_{i}}{\sum_{i=1}^{n} N_{i} \sin \theta_{i}} \\
F S_{\text {Spencer_m }}^{n} & =\frac{\sum_{i=1}^{n}\left(c d l_{i}+N_{i} \tan \phi\right) R}{\sum_{i=1}^{n} w_{i} h_{\text {off }}}
\end{aligned}
$$




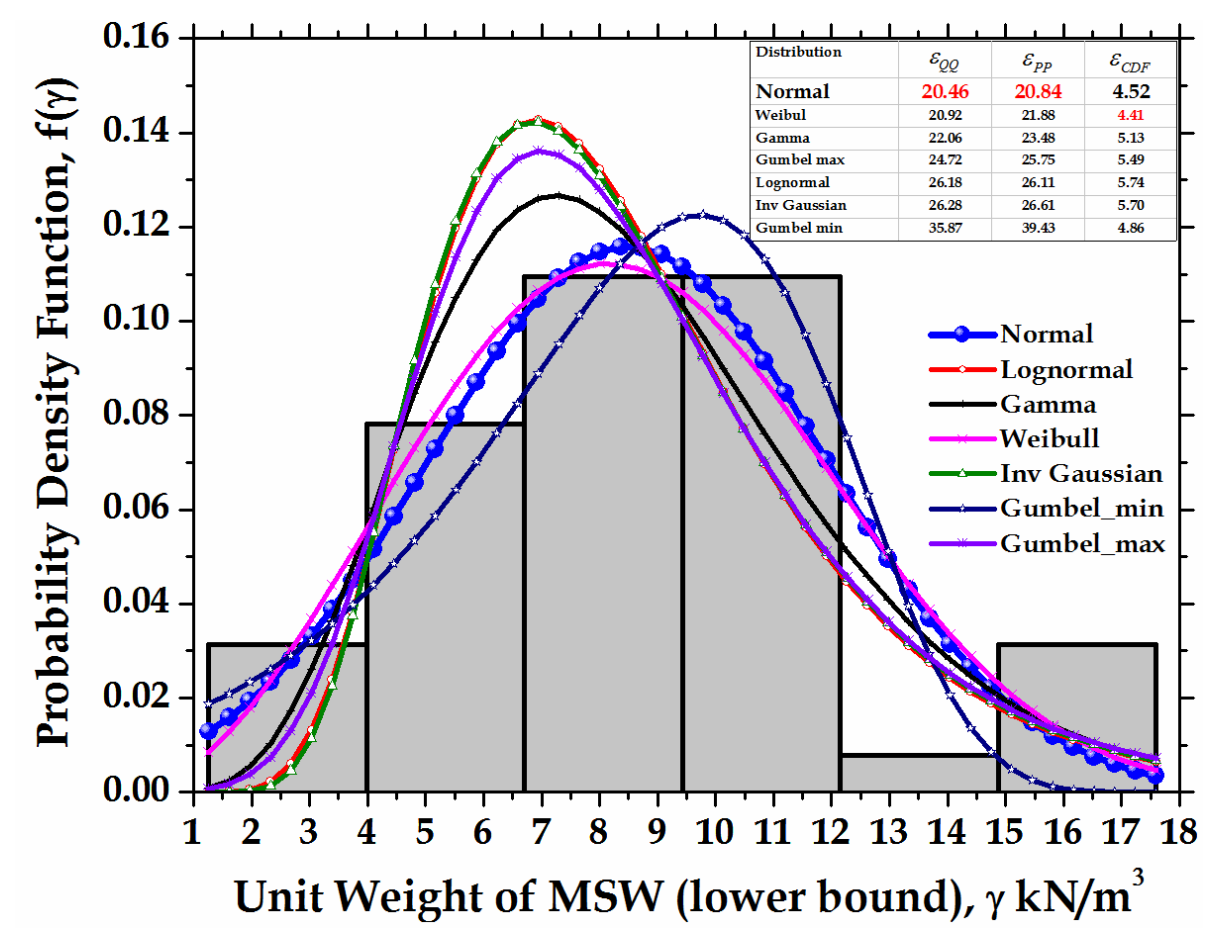

FIG 1. Histogram with theatrical PDF's for unit weight $(\gamma)$ of MSW

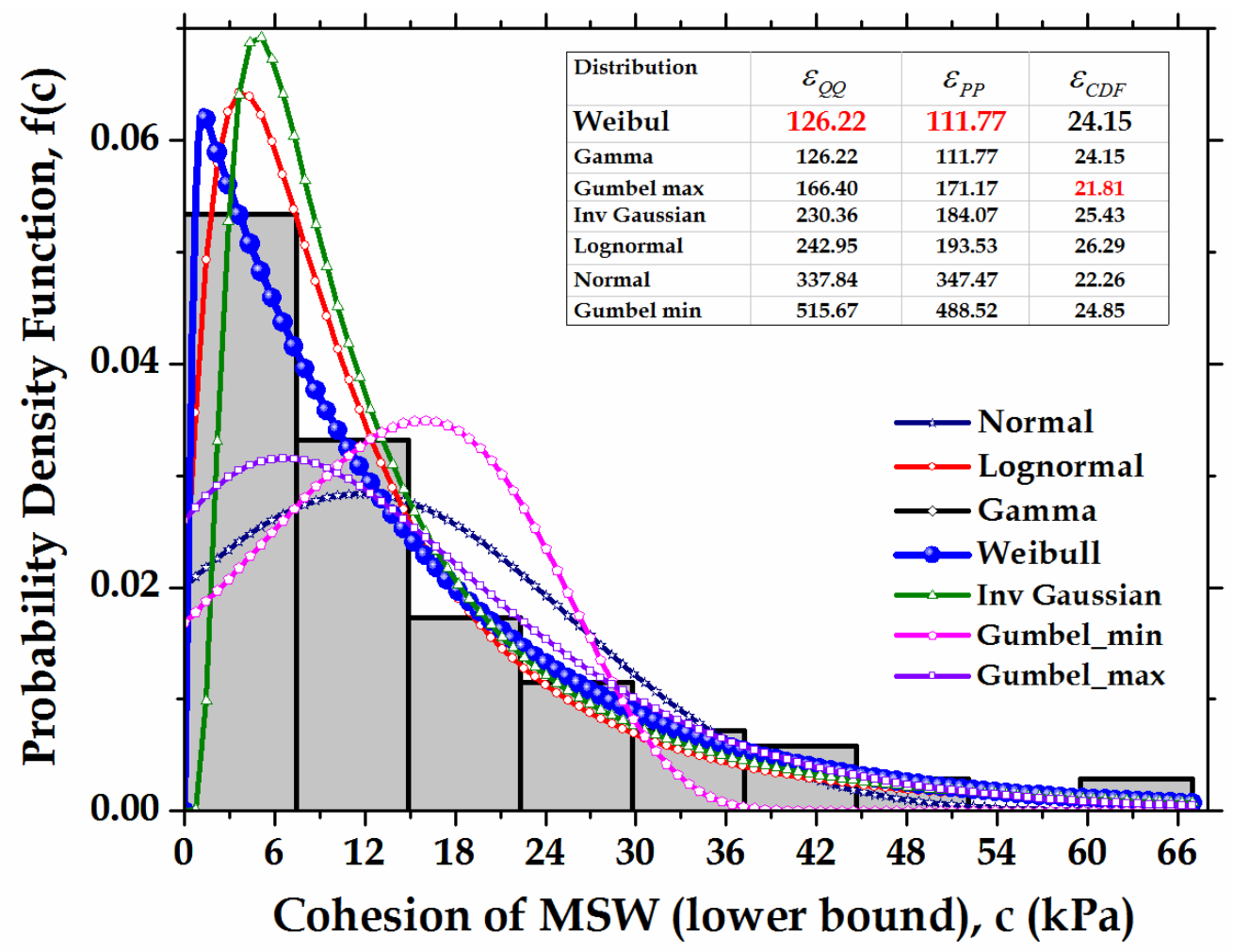

FIG 2. Histogram with theoretical PDF's for cohesion $(c)$ of MSW 


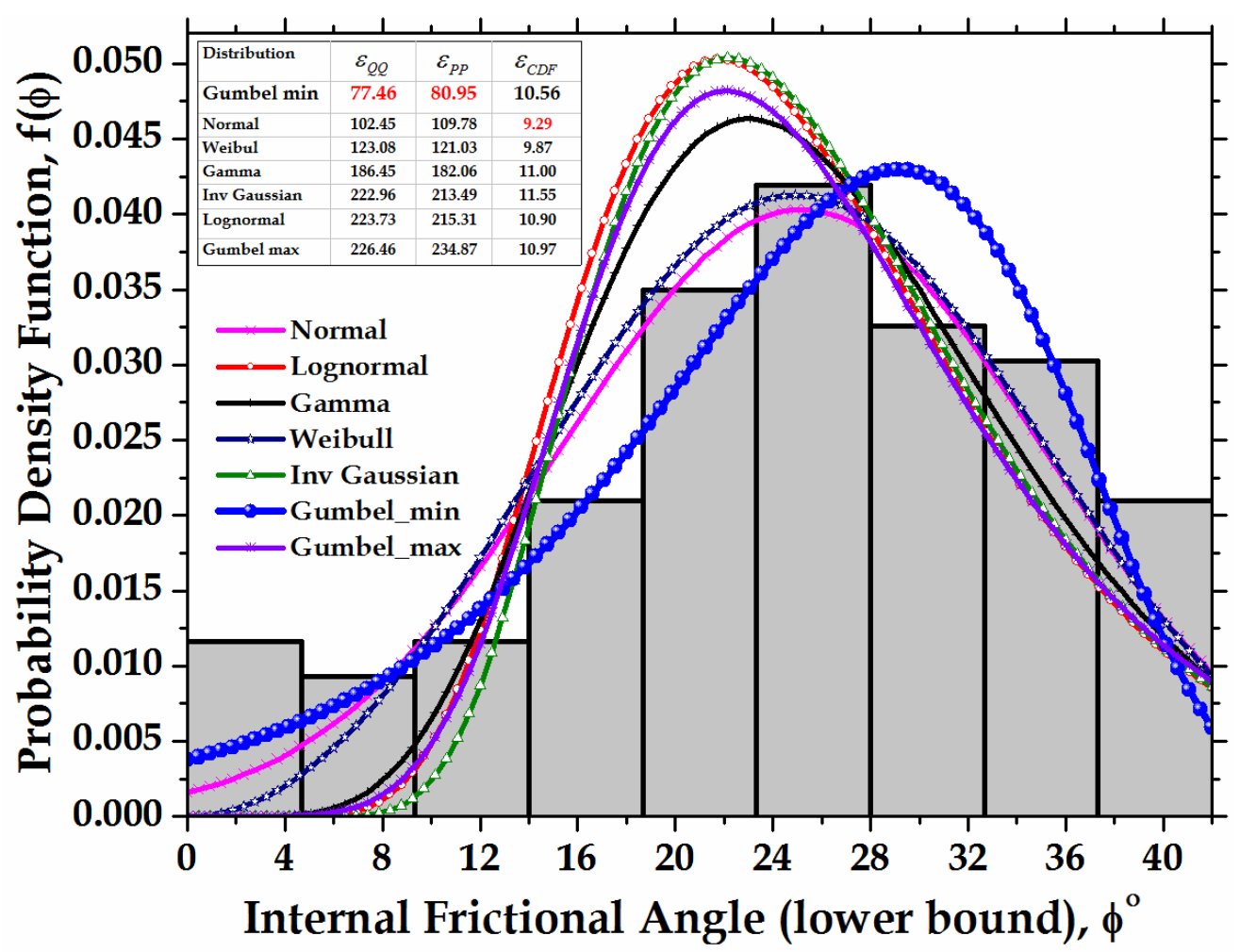

FIG 3. Histogram with theoretical PDF's for friction angle ( $\phi)$ of MSW

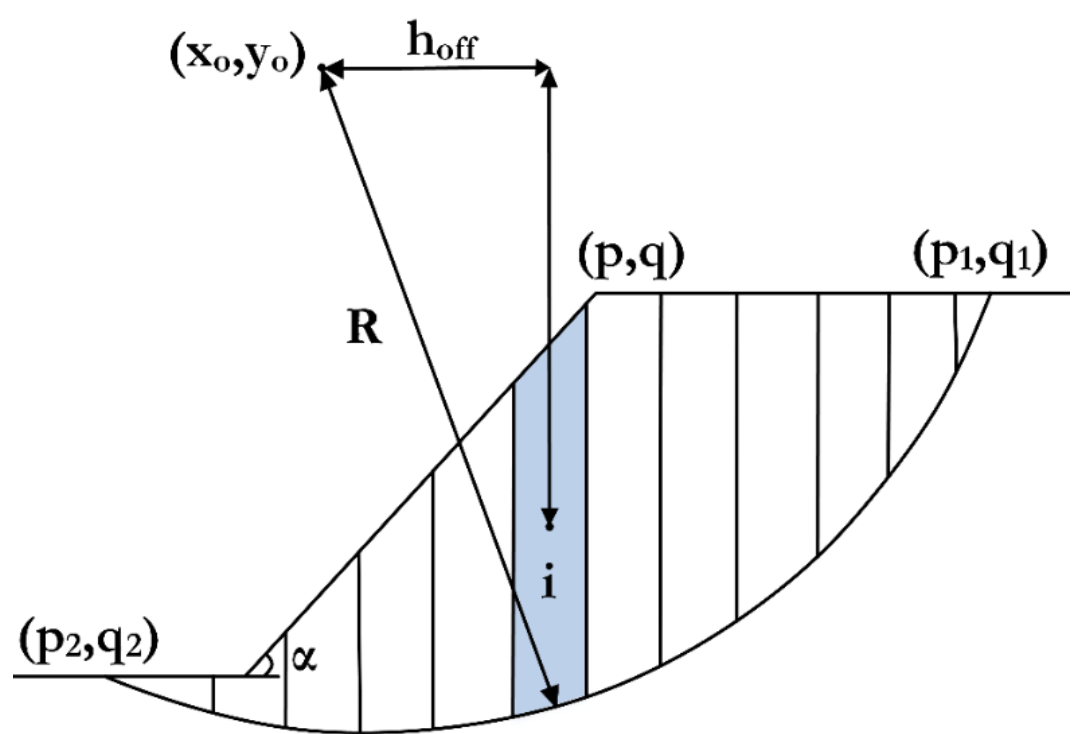

FIG 4(a). Geometry showing the parameters used and moment arms for circular slip surface.

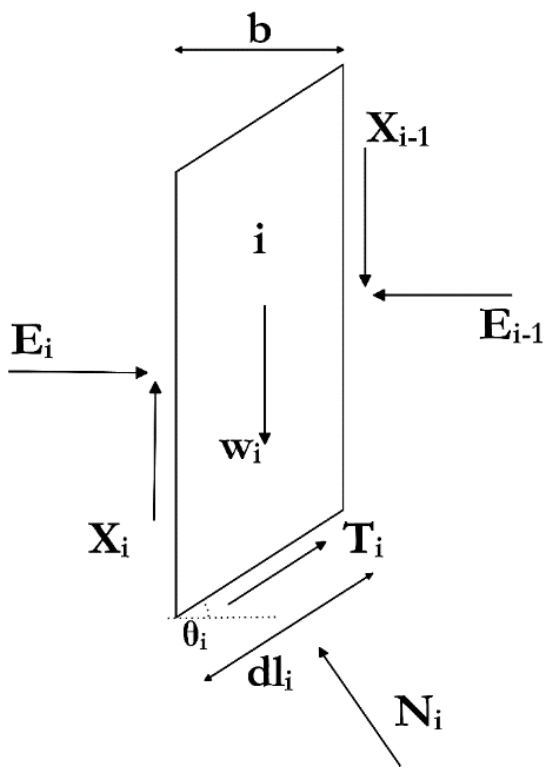

FIG. 4(b). Forces acting on $i^{\text {th }}$ slice. 
Table 1. Optimized values of mean ( $\mu$ ) and coefficient of variation (COV) of MSW properties

\begin{tabular}{|l|c|c|c|}
\hline Variabile & PDF & Mean $(\gamma)$ & $\begin{array}{c}\text { Coefficient of Variation } \\
(\mathrm{COV}) \text { in \% }\end{array}$ \\
\hline$\gamma\left(\mathrm{kN} / \mathrm{m}^{3}\right)$ & Normal & 8.48 & 40.61 \\
\hline$c\left(\mathrm{kN} / \mathrm{m}^{2}\right)$ & Weibull & 14.62 & 100.00 \\
\hline$\phi(\mathrm{deg})$ & Gumbel min & 34.10 & 32.22 \\
\hline
\end{tabular}

where, $\mathrm{N}_{\mathrm{i}}=$ the total normal force on the base of a slice, $\mathrm{T}_{\mathrm{i}}=$ the shear force mobilized on the base of each slice, $\mathrm{c}=$ cohesion, $\delta=$ internal frictional angle, $\mathrm{E}_{\mathrm{i}}=$ the horizontal interslice normal forces, $X_{i}=$ the vertical interslice shear forces, $w_{i}=$ weight of a slice, $\mathrm{h}_{\text {off }}=$ the horizontal distance from the centroid of each slice to the center of rotation ( $\left.=\mathrm{R} \sin \theta_{\mathrm{i}}\right), \mathrm{dl}_{\mathrm{i}}=$ length of slice along the base, $\theta_{\mathrm{i}}=$ the angle between the tangent drawn at the center of the base of each slice and the horizontal, $\mathrm{R}=$ radius of the slip circle.

Now considering the equilibrium of an individual slice, the magnitude of the shear force mobilized at the base of a slice, $T_{i}$ can be written in terms of the Mohr-Coulomb failure criterion as

$$
T_{i}=\tau_{i} d l=\frac{\tau_{f i} d l_{i}}{F S_{\text {Spencer }}}=\frac{(c+\sigma \tan \phi) d l_{i}}{F S_{\text {Spencer }}}
$$

where $\tau_{\mathrm{i}}$ and $\tau_{\mathrm{fi}}$ are the shear stress and shear stress at failure for the $\mathrm{i}^{\text {th }}$ slice. Now, substituting, $\sigma=N_{i} / d l$ in Eq. (3), we get

$$
T_{i}=\frac{c d l_{i}+N_{i} d l_{i} \tan \phi}{F S_{\text {Spencer }}}
$$

Considering the force equilibrium in the vertical direction, we get

$$
w_{i}+X_{i}-X_{i-1}-N_{i} \cos \theta_{i}-T_{i} \sin \theta_{i}=0
$$

Substituting the value of $T_{i}$ in the above equation and solving for $\mathrm{N}_{\mathrm{i}}$, we get,

$$
N_{i}=\frac{w_{i}+X_{i}-X_{i-1}-\frac{c d l_{i} \sin \theta_{i}}{F S_{\text {Spencer }}}}{\cos \theta_{i}+\frac{\tan \phi \sin \theta_{i}}{F S_{\text {Spencer }}}}
$$

Now, consider the equilibrium of the slice in the horizontal direction, we get

$$
\begin{aligned}
& E_{i-1}-E_{i}-N_{i} \sin \theta_{i}+T_{i} \cos \theta_{i}=0 \\
& E_{i}=E_{i-1}-N_{i} \sin \theta_{i}+T_{i} \cos \theta_{i}
\end{aligned}
$$

The inter-slice forces within the sliding mass is defined through a function $f\left(x_{i}\right)$ and a scalar coefficient $\lambda$ as: 
In the above equation $x_{i}$ is the abscissa of the $\mathrm{i}^{\text {th }}$ slice of the slope, $f\left(x_{i}\right)=\tan \delta$ describes the inter-slice variation of shear force $\left(\mathrm{X}_{\mathrm{i}}\right)$ and normal force $\left(\mathrm{E}_{\mathrm{i}}\right)$ across the slope; and ' $\lambda$ ' is the coefficient which represents the percentage of $f\left(x_{i}\right)$ used in the solution. Spencer (1967) assumed $f\left(x_{i}\right)$ is equal to 1 and then $\lambda$ is equal to tan $\delta$, where, $\delta=$ angle of the resultant interslice force with the horizontal. All the above equations are then collectively used to determine the factor of safety $F S_{\text {Spencer }}$ that satisfies both the moment and force equilibrium simultaneously. In order to solve for Spencer method, we initially set, $\mathrm{X}_{\mathrm{i}}-\mathrm{X}_{\mathrm{i}-1}=0$. The equations of $F S_{f_{-} \text {Spencer }}$ and $F S_{m_{-} \text {Spencer }}$ are then calculated to obtain a first set. Also for the first slice, $X_{i}$ is equal to 0 . Then a trial value of ' $\delta$ ' to obtain new estimates for the values of $X_{\mathrm{i}}$ and $\mathrm{E}_{\mathrm{i}}$. Having these values in hand $F S_{f_{-} \text {Spencer }}$ and $F S_{m_{-} \text {Spencer }}$ are recalculated to obtain the new estimates of the factors of safety. This computation is then repeated until the values of the interslice force function converge.

The values of $F S_{f_{-} \text {Spencer }}$ and $F S_{m_{-} \text {Spencer }}$ computed in the above step are not necessarily equal. If $F S_{f_{-} \text {Spencer }} \neq F S_{m_{-} \text {Spencer }}$ means that the moment and force equilibrium are not satisfied simultaneously. Hence the computation must be repeated with various trial values of ' $\delta$ ' until $F S_{f_{-} \text {Spencer }}=F S_{m_{-} \text {Spencer }}$. When the convergence is obtained, that value is then taken as the factor of safety $F S_{\text {Spencer }}=F S_{f_{-} \text {Spencer }}=F S_{m_{-} \text {Spencer }}$ for the slope. The performance function of MSW slope against sliding failure can be expressed as.

$$
g(x)=F S_{\text {Spencer }}-1
$$

The limit state function $\mathrm{g}(\mathrm{x}) \leq 0$, indicates the slope failure and $\mathrm{g}(\mathrm{x})>0$ indicates the stable slope. Now the design point in the standard normal space $\left(u_{k}\right)$ can be expressed as

$$
u_{k}=-\beta_{t} \frac{\sum_{i=1}^{n} \frac{\partial g}{\partial x_{k}} \sigma_{i}}{\sqrt{\sum_{j=1}^{n}\left\{\sum_{i=1}^{n} \frac{\partial g}{\partial x_{k}} \sigma_{i}\right\}^{2}}} \text {, where } k=1,2, \ldots \ldots \mathrm{n}
$$

Where, $\sigma_{i}$ is the standard deviation of a random variable $x_{i}$. Further, the random variable ' $x_{i}^{*}$ ' can be found as follows:

$x_{i}=\sigma_{i} u_{i}+\mu_{i}$

where, $i=1,2, \ldots \ldots$ n and $\mu_{i}$ is the mean of a random variable $x_{i}$. Once we obtain a design point $\left(x_{i}^{*}\right)$, the resistance factors $\left(\Psi_{i}\right)$ for a target reliability index $\left(\beta_{t}\right)$, can be computed using the following equation

$$
\Psi_{\mathrm{i}}=\frac{x_{i}^{*}}{\mu_{i}}
$$




\section{Resistance factors for stability number ( $\left.\Psi_{c / \gamma H}\right)$ and friction angle $\left(\Psi_{\phi}\right)$}

The results presented in Tables $\mathbf{2}$ to $\mathbf{5}$ show the effect of $\operatorname{COV}$ of $c$ and $\phi$ on resistance factors for stability number, $\frac{c}{\gamma H}\left(\Psi_{c / \gamma H}\right)$ and friction angle, $\phi\left(\Psi_{\phi}\right)$ against sliding failure mode for $\beta_{t}=2$ to 4 and for $C O V$ of $\mathrm{c}=20 \%, C O V$ of $\gamma$ ranges from 10 to $30 \%, C O V$ of $\phi$ ranges from 10 to $30 \%$ and for typical value of MSW landfill: $H=10 \mathrm{~m}$, slope angle $(\alpha)=26.56^{\circ}$, cohesion $(c)=14.62 \mathrm{kN} / \mathrm{m}^{2}$, friction angle $(\phi)=34.14^{\circ}$, unit weight $(\gamma)=8.48 \mathrm{kN} / \mathrm{m}^{3}$. The resistance factors for stability number, $\frac{c}{\gamma H}\left(\Psi_{c / \gamma H}\right)$ and friction angle, $\phi\left(\Psi_{\phi}\right)$ for $\beta_{t}=2$ to 4 are presented in Tables $\mathbf{2}$ to $\mathbf{5}$. It can be noted from Tables $\mathbf{2}$ to $\mathbf{5}$ that the resistance factors are reduced when the target value of reliability index $\left(\beta_{t}\right)$ increases from 2 to 4 . It may be observed from Table 2 that for a constant value of $\operatorname{COV}$ of $\phi$, resistance factor for stability number ( $\Psi_{c / \gamma H}$ ) marginally increases with increase in $\operatorname{COV}$ of $\phi$ from $10 \%$ to $30 \%$. Whereas, the resistance factor for friction angle $\left(\Psi_{\phi}\right)$ significantly reduces with increase in COV of $\phi$ from $10 \%$ to $30 \%$. Moreover, an important observation that can be made from Tables 2 to 4 that for constant values of $\operatorname{COV}$ of $c$ and $\operatorname{COV}$ of $\phi, C O V$ of $\gamma$ has a considerable effect on resistance factors for stability number, $\frac{c}{\gamma H}\left(\Psi_{c / \gamma H}\right)$ and friction angle, $\phi\left(\Psi_{\phi}\right)$ for a given reliability index. Another important observation can be made from Table 5 that for constant values of $\operatorname{COV}$ of $\phi$ and $C O V$ of $\gamma$, a significant reduction in the magnitude of $\Psi_{c / \gamma H}$ from 0.83 to 0.21 can be observed with increase in $\operatorname{COV}$ of $\frac{c}{\gamma H}$ from 20 to $40 \%$. Whereas, a marginal increase in the magnitude of $\Psi_{\phi}$ can be observed with increase in $C O V$ of $\frac{c}{\gamma H}$ from 20 to $40 \%$. Therefore, the influence of $\operatorname{COV}$ of $c, \operatorname{COV}$ of $\phi$ and $C O V$ of $\gamma$ for the stability of MSW slope may not be neglected as they are significant random variables.

Table 2. Influence of $\mathrm{COV}$ of $\boldsymbol{c}$ and $\phi$ on the resistance factors $\Psi_{c / \gamma H}$ and $\Psi_{\phi}$ for a target reliability $\left(\beta_{t}\right)$ for COV of $c=20 \%$ and $\operatorname{COV}$ of $\gamma=10 \%$

\begin{tabular}{|c|c|c|c|c|c|c|}
\hline \multirow{2}{*}{$\beta_{t}$} & \multicolumn{2}{|c|}{ COV of $\phi=10 \%$} & \multicolumn{2}{c|}{ COV of $\phi=20 \%$} & \multicolumn{2}{c|}{ COV of $\phi=30 \%$} \\
\cline { 2 - 7 } & $\Psi_{c / \gamma H}$ & $\Psi_{\phi}$ & $\Psi_{c / \gamma H}$ & $\Psi_{\phi}$ & $\Psi_{c / \gamma H}$ & $\Psi_{\phi}$ \\
\hline 2.0 & 0.78 & 0.84 & 0.83 & 0.68 & 0.85 & 0.55 \\
\hline 2.5 & 0.71 & 0.81 & 0.77 & 0.62 & 0.79 & 0.49 \\
\hline 3.0 & 0.63 & 0.78 & 0.70 & 0.58 & 0.72 & 0.43 \\
\hline 3.5 & 0.55 & 0.75 & 0.63 & 0.53 & - & - \\
\hline 4.0 & 0.47 & 0.72 & 0.54 & 0.50 & - & - \\
\hline
\end{tabular}


Table 3. Influence of $\mathrm{COV}$ of $c$ and $\phi$ on the resistance factors $\Psi_{c / \gamma H}$ and $\Psi_{\phi}$ for a target reliability $\left(\beta_{t}\right)$ for $C O V$ of $c=20 \%$ and $C O V$ of $\gamma=20 \%$

\begin{tabular}{|c|c|c|c|c|c|c|}
\hline \multirow{2}{*}{$\beta_{t}$} & \multicolumn{2}{|c|}{ COV of $\phi=10 \%$} & \multicolumn{2}{c|}{ COV of $\phi=20 \%$} & \multicolumn{2}{c|}{ COV of $\phi=30 \%$} \\
\cline { 2 - 7 } & $\Psi_{c / \gamma H}$ & $\Psi_{\phi}$ & $\Psi_{c / \gamma H}$ & $\Psi_{\phi}$ & $\Psi_{c / \gamma H}$ & $\Psi_{\phi}$ \\
\hline 2.0 & 0.67 & 0.85 & 0.75 & 0.69 & 0.77 & 0.56 \\
\hline 2.5 & 0.57 & 0.82 & 0.66 & 0.64 & 0.68 & 0.50 \\
\hline 3.0 & 0.47 & 0.79 & 0.56 & 0.59 & 0.58 & 0.45 \\
\hline 3.5 & 0.36 & 0.76 & 0.46 & 0.55 & - & - \\
\hline 4.0 & 0.25 & 0.74 & 0.34 & 0.52 & - & - \\
\hline
\end{tabular}

Table 4. Influence of $C O V$ of $c$ and $\phi$ on the resistance factors $\Psi_{c / \gamma H}$ and $\Psi_{\phi}$ for a target reliability $\left(\beta_{t}\right)$ for $C O V$ of $c=20 \%$ and $C O V$ of $\gamma=30 \%$

\begin{tabular}{|c|c|c|c|c|c|c|}
\hline \multirow{2}{*}{$\beta_{t}$} & \multicolumn{2}{|c|}{ COV of $\phi=10 \%$} & \multicolumn{2}{c|}{ COV of $\phi=20 \%$} & \multicolumn{2}{c|}{ COV of $\phi=30 \%$} \\
\cline { 2 - 7 } & $\Psi_{c / \gamma H}$ & $\Psi_{\phi}$ & $\Psi_{c / \gamma H}$ & $\Psi_{\phi}$ & $\Psi_{c / \gamma H}$ & $\Psi_{\phi}$ \\
\hline 2.0 & 0.52 & 0.86 & 0.62 & 0.70 & 0.66 & 0.57 \\
\hline 2.5 & 0.38 & 0.83 & 0.49 & 0.65 & 0.53 & 0.51 \\
\hline 3.0 & 0.23 & 0.81 & 0.36 & 0.61 & 0.38 & 0.47 \\
\hline
\end{tabular}

Table 5. Influence of $\mathrm{COV}$ of $c$ and $\phi$ on the resistance factors $\Psi_{c / \gamma H}$ and $\Psi_{\phi}$ for a target reliability $\left(\beta_{t}\right)$ for COV of $\gamma=10 \%$ and COV of $\phi=20 \%$

\begin{tabular}{|c|c|c|c|c|}
\hline \multirow{2}{*}{$\beta_{t}$} & \multicolumn{2}{|c|}{ COV of $c=20 \%$} & \multicolumn{2}{c|}{ COV of $c=40 \%$} \\
\cline { 2 - 5 } & $\Psi_{c / \gamma H}$ & $\Psi_{\phi}$ & $\Psi_{c / \gamma H}$ & $\Psi_{\phi}$ \\
\hline 2.0 & 0.83 & 0.68 & 0.53 & 0.71 \\
\hline 2.5 & 0.77 & 0.62 & 0.38 & 0.66 \\
\hline 3.0 & 0.70 & 0.58 & 0.21 & 0.62 \\
\hline
\end{tabular}

\section{CONCLUSIONS}

Load resistance factor design (LRFD) procedure that considers variability associated with the design of MSW landfill slopes is illustrated in the paper. The resistance factors that are developed with the assumption of normal or lognormal distributions for unit weight $(\gamma)$, cohesion $(c)$ and internal friction angle $(\phi)$ may be either underestimated or overestimated. It is recommended from the present study that the normal, Weibull and Gumbel minimum distributions are good models for the experimentally observed values of unit weight $(\gamma)$, cohesion $(c)$ and internal friction angle $(\phi)$ respectively. In addition, the optimized values of mean and standard deviation of MSW properties provided in the study are used to determine the resistance factor for stability number and friction angle. The effect of $C O V$ of $c, C O V$ of $\phi$ and $C O V$ of $\gamma$ on the resistance 
factors for stability number, $\frac{c}{\gamma H}\left(\Psi_{c / \gamma H}\right)$ and friction angle, $\phi\left(\Psi_{\phi}\right)$ is significant and should be given due consideration for the probabilistic and less conservative designs.

\section{REFERENCES}

Basha, B.M., and Babu, G.LS. (2014). "Reliability-based load and resistance factor design approach for external seismic stability of reinforced soil walls." Soil Dynamics and Earthquake Engineering Vol. 60: 8-21

Basha, B.M., and Babu, G.LS. (2013). "Reliability based LRFD approach for external stability of reinforced soil walls." Indian Geotechnical Journal, 43(4): 292-302.

Bhattacharya, G. and Dey, S. (2010). "Reliability evaluation of earth slopes by first order reliability method." Proc. of Indian Geotechnical Conference, IGC-2010, Dec. 16-18, Bombay: 1069-1072.

Hassan, F., Ahmed M., and Wolff, T.F. (1999). "Search algorithm for minimum reliability index of earth slopes." J. Geotechnical \& Geoenv. Engrg., Vol. 125(4): 301-308.

Low, B.K. (2003). "Practical probabilistic slope stability analysis." Proc. soil and rock America, Vol. 2: 2777-2784.

Malkawi, A.I., Husein, W., Hassan, F. and Sarma, K.S. (2001). "An efficient search method for finding the critical circular slip surface using the Monte Carlo technique." Canadian Geotechnical Journal, Vol. 38(5): 1081-1089.

Spencer, E. (1967), "A method of analysis of the stability of embankments assuming parallel inter-slice forces", Geotechnique, Vol. 17(1): 11-26.

Xue, J. and Gavin, K. (2007). "Simultaneous determination of critical slip surface and reliability index for slopes." J. Geotechnical \& Geoenv. Engrg., Vol. 133: 878-886. 